Archived version from NCDOCKS Institutional Repository http://libres.uncg.edu/ir/asu/

\title{
Appalachľan
}

B O O N E, N O R T H C A R O L I N A

\section{The GamerGate Controversy And Journalistic Paradigm Maintenance}

\author{
By: Gregory Perreault and Tim Vos
}

\begin{abstract}
GamerGate is a viral campaign that became an occasion, particularly from August 2014 to January 2015, to both question journalistic ethics and badger women involved in game development and gaming criticism. Gaming journalists thus found themselves managing a debate on two fronts: defending the probity of gaming journalism and remediating attacks on women. This study explores how gaming journalists undertook paradigm maintenance in the midst of the controversy. This was analyzed through interviews with gaming journalists as well as a discourse analysis of the texts responding to GamerGate that were produced by their publications. Although gaming journalists operate within a form of lifestyle journalism, the journalists repaired their paradigm by linking their work to traditional journalism and emphasizing a paternal role.
\end{abstract}

Perreault GP, Vos TP. The GamerGate controversy and journalistic paradigm maintenance. Journalism. 2018;19(4):553-569. doi:10.1177/1464884916670932. Publisher version of record available at: https://journals.sagepub.com/doi/full/10.1177/1464884916670932 


\title{
The GamerGate controversy and journalistic paradigm maintenance
}

\author{
Gregory P Perreault \\ Appalachian State University, USA
}

\section{Tim P Vos}

University of Missouri, USA

\begin{abstract}
GamerGate is a viral campaign that became an occasion, particularly from August 2014 to January 2015 , to both question journalistic ethics and badger women involved in game development and gaming criticism. Gaming journalists thus found themselves managing a debate on two fronts: defending the probity of gaming journalism and remediating attacks on women. This study explores how gaming journalists undertook paradigm maintenance in the midst of the controversy. This was analyzed through interviews with gaming journalists as well as a discourse analysis of the texts responding to GamerGate that were produced by their publications. Although gaming journalists operate within a form of lifestyle journalism, the journalists repaired their paradigm by linking their work to traditional journalism and emphasizing a paternal role.
\end{abstract}

\section{Keywords}

GamerGate, gaming journalism, journalism scandal, lifestyle journalism, paradigm repair

\section{Introduction}

What began as a blog attack by an ex-boyfriend against a female video game developer led to an Internet phenomenon that raised questions about the ethics of gaming

\footnotetext{
Corresponding author:

Gregory P Perreault, Department of Communication, Appalachian State University, 245 Walker Hall, Boone, NC 28607, USA.

Email: perreaultgp@appstate.edu
} 
journalism. Writing on a blog, Eron Gjoni accused his former girlfriend of sleeping with a prominent gaming journalist, Nathan Grayson of Kotaku, to obtain better news coverage for her game (Kaplan, 2014). Kotaku quickly disproved this claim, demonstrating that while Grayson had been in a relationship with the developer, Zoe Quinn, he had never reported on her game and did not cover her work after they began a relationship. But as sometimes happens on the Internet, the questions raised became more interesting than the answers. Critics used the Twitter hashtag \#gamergate to argue that gaming journalists were too connected to the gaming industry, actively colluding with the industry to promote a social justice agenda and focusing on cultural/social aspects of games as opposed to assessing their technical and play features. Simultaneously, the hashtag was used to harass women and minorities in game development and gaming criticism through death threats and doxing - researching and releasing the personal information of game developers and critics (Chess and Shaw, 2015). Women were disproportionately targeted (Massanari, 2015). Throughout the GamerGate controversy, gaming journalists were called upon to explain and defend their role. Gaming journalism was suddenly being attacked on two fronts: regarding 'the relationships between independent game developers and the press' (Golding, 2014) and as quasi-representatives of the gamers who 'make the gaming community an unwelcoming space for women and other marginalized groups' (Cote, 2015: 18). Journalists responded to these accusations by articulating their journalistic roles and their professional ethics.

This study explores the paradigm maintenance performed by gaming journalists early in the GamerGate controversy. In the wake of ethical controversies, journalists commonly take the occasion to reaffirm the legitimacy of their paradigm (Berkowitz, 2000). With this in mind, this study draws on comments about GamerGate from in-depth interviews conducted during the controversy with 17 gaming journalists and from the published responses to criticism, either from the journalists themselves or from their news organization. Discourse analysis of their responses addresses how gaming journalists articulated their role during the controversy and how gaming journalists performed paradigm repair.

Much like sports journalism and technology journalism, much of gaming journalism operates as an 'enthusiast-press' (Carlson, 2009: 4,10) and is somewhat reliant on cooperation from industry officials it covers. Gaming journalists rely on industry officials in order to obtain early copies of the games they review. The nature of this relationship is familiar in lifestyle journalism - fashion, travel, film, television, and personal technology reporters similarly rely on industry officials in order to do their work.

While the connections between journalism and the market may be stronger in gaming journalism, the connection certainly persists in other journalism niches. GamerGate would have been a classic journalistic ethical controversy, but for the integral gendered aspect to the controversy. While many GamerGate supporters stated that their aim is to see change in gaming journalism, another aspect of the controversy is the harassment of female game developers and public relations people - who were accused of adversely affecting the quality of gaming journalism. Understanding how journalists worked to maintain their paradigm while negotiating the harassment conducted by a portion of their audience helps provide shape to how gaming journalists conceive of their role within the journalistic field. It also helps shed light on how they maintained that role in the midst of 
controversy. This is valuable for journalism studies in that such analysis reveals norms and operations within the growing enthusiast-press.

\section{Literature review}

\section{Paradigm repair}

In his foundational work, Kuhn (2012 [1970]) argues that paradigms are foundational systems that shape the conceptualized boundaries, norms, and practices of a given profession. A paradigm consists of

broadly shared assumptions about how to gather and interpret information relevant to a particular sphere of activity ... When a group acquires near-universal faith in the validity of a system of representing and applying information, that system attains paradigmatic standing. (Bennett et al., 1985: 54)

Paradigms are rarely explicit, more often unwritten and unspoken norms that are learned through having experience in a field. Paradigms tend to be hegemonic in nature in that a member of the field must stay within a paradigm in order to be a respected member of the community (Reese, 1990) and to maintain authority (Coddington, 2012). As Coddington (2012) concludes, 'Journalism exhibits many of the characteristics of a profession guided by paradigms’ (p. 280). Paradigm shifts, however, disrupt and reshape a field (Kuhn, 2012 [1970]). This happens gradually through the identification of problems that are unaddressed by the paradigm. Those within a field tend to respond to attacks on their paradigm by trying to either diminish the problem or by demonstrating how the existing paradigm addresses the problems.

Prior research has found that, when journalists are being critiqued for ethical lapses, they engage in paradigm repair as a way of normalizing the situation (Bennett et al., 1985; Hindman and Thomas, 2013; Zelizer, 2004). While elements of the GamerGate controversy make it a unique situation, the key element of this study - the journalists' response as a method of repairing the paradigm - is a standard feature in paradigm maintenance (Berkowitz, 2000; Hindman, 2005; Hindman and Thomas, 2013). Critiques can come from at least three different places: from within the journalistic field, as was the case in the Jayson Blair scandal at The New York Times (Hindman, 2005); from other social institutions, such as the government in the case of journalist Helen Thomas' comments about Jews (Hindman and Thomas, 2013); or from the public, as was the case with the death of Princess Diana (Berkowitz, 2000). Avenues for public criticism had been limited in the past, largely confined to letters to the editor. With the rise of social media, the public is increasingly able to engage in criticism of journalism. Knowing who is criticizing journalism and who is doing the paradigm repair is important to how the repair work occurs (Berkowitz, 2000).

Beyond respecting the norms of their professional community, journalists must also reinforce and affirm them, particularly in the face of criticism (Zelizer, 2004). Paradigm repair is 'the notion that when journalists perceive an event or situation as undermining journalists' or news organizations' credibility and authority they will go to great efforts to restore their own image and reputation' (Steiner et al., 2013: 705-706). Berkowitz 
(2000) notes that paradigm repair accomplishes the 'double duty' of 'outlining the boundaries of the community' by reaffirming professional norms for the public (p. 127).

Journalists' paradigm repair typically operates through the use of editorials and opinion pieces that identify the wrongdoing and indicate how that wrongdoing occurred (Bennett et al., 1985; Berkowitz, 2000). Scholars have examined paradigm repair as occurring in controversies as diverse as the death of Princess Diana, when the tabloids' behavior was blamed for the crash leading to her death (Berkowitz, 2000; Hindman, 2003), the revelation that The New York Times reporter Jayson Blair had fabricated and plagiarized stories (Hindman, 2005) and the demise of the Rocky Mountain News and the Seattle Post-Intelligencer (Carlson, 2012). In the case of each controversy, the unwritten assumptions of the journalistic paradigm were challenged, prompting journalists to engage in paradigm repair. It should be noted that in the earlier examples, the claims leveled against journalism were true, whereas many of the most specific claims of GamerGate were false. Yet journalists responded to the claims and in so doing, maintained their paradigm. Hence, GamerGate still operates as a classic paradigmatic attack.

Much of early gaming journalism operated as a sort of buyer's guide - it provided advice, either explicitly or implicitly, through its criticism about what to purchase. Some of the earliest gaming journalism - in particular at Nintendo Power and Sega Visions was actually marketing, the magazines themselves supported by video game companies. Yet, this buyer's guide journalism is the sort of 'objective' journalism many GamerGate supporters desired (Foxman and Nieborg, 2016) - however, many gaming journalism outlets broadened their role to address cultural and social issues in games. Hanusch (2014) describes this type of journalism as lifestyle journalism. It is a market-driven form of journalism in which Hanitzsch (2007) argues, 'lifestyle journalism exemplifies [the] trend toward a blending of information with advice and guidance' (p. 375). Gaming journalism is emblematic of that trend, particularly in its emphasis on giving purchasing advice.

Classic journalistic conceptions of news tend to look down on lifestyle journalism, but the role of giving advice and guidance can actually be socially valuable (Hanusch, 2014). Thomas (2016), seeking to rehabilitate a notion of paternalism, argues that journalists play a valuable role as a citizen's guide. 'Paternalism calls for a journalism that gives people the tools they need to flourish ... and address those issues that prevent them from doing so' (Thomas, 2016: 96). Conceptualized this way, the paternalistic role goes beyond purchasing guidance to how to live, vote, and behave as citizens. Of course, paternalism has other meanings. It also refers to a kind of authority that would save persons from their own poor decisions and discipline them toward more responsible behavior (Thomas, 2016).

\section{Role conception}

All of this suggests that gaming journalists, like other kinds of lifestyle journalists, perform a different kind of role relative to the rest of the journalistic field. But, since journalists typically find their 'professional identities' in their roles (Johnstone et al., 1972: 131), and since roles are generally articulated relative to contributions to democracy (Christians et al., 2009), gaming journalists are bound to struggle to articulate 
their identity in the absence of clear democratic functions. Fürsich (2012: 22) found that lifestyle journalists articulate their role in developing a 'close connection to the audience', 'following trends' and blurring the 'boundaries between news and entertainment'. Roles function as important forms of social stability - giving journalists a clear sense of self-identity, and also establishing a clear social-identity (Christians et al., 2009). Established roles insulate journalists from attacks from the public and from other institutions by providing an agreed upon set of role-related practices and tools (Hanitzsch, 2007).

Some of the early scholarship on journalistic roles, however, was less narrowly focused on justifying roles in terms of contributions to democratic self-governance. Lasswell (1948), for instance, identified three media roles: 'surveillance of the environment', 'the correlation of the parts of society in responding to the environment', and 'the transmission of the social heritage from one generation to the next' (p. 38). Wright (1960) added 'entertainment' as a fourth role or function (p. 16). Subsequent research by Weaver and Wilhoit $(1991,1996)$ identified other roles: dissemination, interpretation, adversarial, and, later, populist mobilizer (Weaver et al., 2007). These role conceptions, while not inherently expressive of democratic values, nevertheless express forms of journalism that fit within democratic theories of the press (Christians et al., 2009). But, these role conceptions - apart from the democratic implications - still provide journalists, regardless of their beat, with a framework for doing their jobs.

These roles are largely descriptive, rather than injunctive, norms (Lapinski and Rimal, 2005). While these roles or functions describe journalists' approach to journalism (they are norms in as much as they are normal), they do not capture the normative nature of roles as the good, right, and moral rules for the journalistic field. Journalists typically defend descriptive roles because they are so closely identified with the identity of journalism (Berkowitz, 2000), but journalists also turn to normative roles as a form of legitimacy, since they root journalism in pro-social values and shared societal beliefs (Christians et al., 2009). Again, given that gaming journalists cannot easily appeal to norms rooted in democratic service, it seems reasonable to explore how they do articulate their role.

Hence, we pose the following research questions:

$R Q 1$. How do gaming journalists articulate their role, particularly in relation to the gaming industry?

$R Q 2$. How do gaming journalists engage in paradigm repair in addressing the GamerGate controversy?

\section{Method}

In order to gauge how journalists responded to the GamerGate controversy, we interviewed 17 journalists who cover gaming at niche journalism publications and collected the GamerGate-related editorials, opinion, analysis, and interpretative pieces produced by those publications. Many gaming journalism websites drew little differentiation between editorials and opinion pieces in that, as enthusiast media, they tend to 
emphasize the personalities of their reporters, with much of gaming journalism falling broadly into the category of opinion (Nieborg and Sihvonen, 2009). Editorials and opinion pieces written by journalists can be considered 'as close as is possible to being an institutional voice' (Hindman, 2003: 671) in that they 'provide views of media professionals on issues pertaining to media norms, values, and responsibilities' (Hindman and Thomas, 2013: 272). Most studies of paradigm repair focus solely on textual analysis in order to infer about the paradigm that created the texts. This study hopes to bring additional insight into the paradigm maintenance process by learning about the agents who undertake paradigm maintenance. In-depth interviews provide useful supplemental forms of data by providing interpretation, summary, and integration (Weiss, 1994). In addition, interviews help researchers understand the complicated processes that lead to the content produced (Gans, 1979).

The 17 journalists interviewed included writers, editors, and columnists at different organizational levels, ranging from editor-in-chief to contributor. They were interviewed in the earliest, peak months of GamerGate, from August to December 2014. Since the GamerGate controversy included harassment of gaming journalists - particularly female journalists - some publications chose not to participate, despite potentially having a perspective to add to the story. Only two women consented to be interviewed. Most interviewees were male and white. In short, the majority of interviewees were not subject to the worst harassment and felt comfortable enough to discuss a controversy potentially endangering their journalistic niche and certainly endangering some of their colleagues.

The publications where journalists worked - and whose texts were analyzed - included Kotaku, Polygon, Verge, Joystiq, RPGFan, RPGamer, PC Gamer, The Guardian, The New York Times, Entertainment Weekly, IGN, Forbes, VICE, and a former editor at GamePro magazine. The outlets selected reflect an array of different media models and journalistic approaches. GamePro and Electronic Gaming Monthly represent the old guard of fan-oriented magazines, which are heavily subsidized by advertisements from video game companies. The New York Times and The Guardian are international newspapers that in recent years have reported on video games through their personal technology and arts departments. Forbes is a traditional business magazine that has spawned a lively blog on its website dedicated to television, movies, and digital games. Entertainment Weekly has long covered games from an entertainment standpoint. IGN, Kotaku, Polygon, Joystiq, ${ }^{1}$ RPGFan, and RPGamer represent a new wave of gaming journalism that is online-only, emphasizing aggregation, a mixture of short news briefs, longer reviews, and first-person reflections.

Since gaming journalism columns and websites are not uniformly cataloged via Lexis Nexus or similar services, individual articles were identified through using the native search function on the news website of each journalist interviewed for this research. This resulted in 32 total editorials and opinion pieces from these websites between August 2014 and January 2015 - during the peak of the GamerGate controversy in which most press responses took place.

Discourse analysis was employed in analyzing the articles and interview texts. Discourse analysis brings to the foreground the discursive strategies and techniques used by writers and speakers to create meaning; it is attentive to word choice, metaphors, and lines of argument (Alba-Juez, 2009; Hall, 1980; van Dijk, 1988). Discourse analysis 
locates discourse within social and institutional contexts (Burr, 1995; van Dijk, 1977), which is particularly appropriate for understanding how journalists discursively construct their work. This form of analysis is useful in that we are most interested in the discursive strategies employed in paradigm repair. Researchers paid attention to the emergence of themes in the strategies employed in both interview discussion of GamerGate and in text responses. The data was examined and then the researchers separately proposed discursive themes that emerged until we reached consensus.

The interviews with gaming journalists were conducted during the controversy. The controversy did involve danger to journalists, since some faced death threats and some had their personal information hacked and posted online. Given these dangers, this study granted anonymity to interviewees. Under the approval of the Institutional Review Board and in accordance with the style of the American Psychological Association, individual journalists were assigned a letter, with the corresponding interview subject known only by the researcher. Conducting the interviews from the beginning and throughout GamerGate meant that the authors were able to get robust interview data regarding paradigm work. It should be noted that the journalists who were interviewed were not necessarily those whose texts were analyzed.

\section{Background}

In order to interpret the discourse occurring in gaming journalism, it would be useful to place the findings in the context of the controversy and the culture that led to the controversy.

The controversy developed in three ways. First, it created a discussion about journalism ethics. Jenni Goodchild's blog about GamerGate collected the charges from anonymous posters: that gaming journalists were not transparent about their personal and professional connections to game developers, that gaming journalists were pushing a social justice agenda (Goodchild, 2014a), that academics involved in the Digital Games Research Association were conspiring with journalists to shift the agenda (Chess and Shaw, 2015; Goodchild, 2014a), and that gaming journalists on a private mailing list were colluding to shape game coverage (Goodchild, 2014a). The charges of collusion seemed to have some support among critics when, from 28 to 30 August 2014, numerous news organizations, including Kotaku, Wired, The Guardian, and Polygon, published articles arguing 'gamers are dead' (Massanari, 2015). The charges of an academic conspiracy and institutional collusion were dismissed in large part, although discussion of the other charges continues in GamerGate circles. This was a discussion gaming journalists largely engaged and welcomed.

Second, female game developers and critics suffered through a sustained campaign of misogynistic attacks (Golding, 2014) largely stemming from its origins in a malecentric gaming culture. This culture was developed in no small part through early gaming journalism itself (Cote, 2015). Nintendo Power in the 1990s did not 'treat women as equal members of the gaming community' (Cote, 2015: 16-17). With this context in mind, the developing audience for gaming - now nearly half female (Casti, 2014) might be a reason for the early, cultivated, and exclusionary masculine audience to feel threatened. 
The GamerGate controversy emerged out of digital forums like Reddit, 4chan, and 8 chan that 'exhibit the tendency to view women as either objects of sexual desire or unwelcome interlopers or both' (Massanari, 2015: 8). Gjoni, the jilted ex-lover of Zoe Quinn made his initial post in the SomethingAwful forums, charging Quinn with using intimate relationships with gaming journalists, in particular Nathan Grayson of Kotaku, in order to obtain better coverage (Kaplan, 2014) - these charges later moved to other forums (Chess and Shaw, 2015; Massanari, 2015). These accusations reached an audience online when actor and conservative pundit Adam Baldwin coined the hashtag \#gamergate and tweeted two videos attacking Quinn. Chess and Shaw (2015) noted that Baldwin's '190k plus followers quickly helped the hashtag spread, which then spawned Web sites, reddit subthreads, additional 4chan and then 8chan threads, and a sustained online movement' (p. 210). Golding (2014) argued that the viciousness of the GamerGate controversy evidenced 'the end of gamers and the viciousness that accompanies the death of an identity' (Golding, 2014). In the most widely reported situations, Quinn, game developer Brianna $\mathrm{Wu}$, and gaming critic Anita Sarkessian received death threats and had their personal information, such as address and phone number, published online (Golding, 2014).

Third, in part through the attention of conservative pundits, critics questioned the authority of game journalists to critique sexist and violent depictions in video games. Why, the critics asked, couldn't the journalists just focus on games for what they were - a type of technical pastime - and avoid 'political correctness' altogether?

\section{Findings}

In the face of the controversy, journalists articulated two distinct roles - that of a paternal figure and that of a traditional journalist. Meanwhile, journalists engaged in paradigm repair by distancing themselves from the hostile activities of some of their readers and by linking their work to classic journalistic entities. These strategies largely map onto the two roles identified. Thus, in the analysis that follows, paradigm repair activities are discussed in conjunction with the roles that gaming journalists articulated.

\section{Role of the paternal figure}

In the midst of the GamerGate controversy, one way that journalists articulated their role was as a sort of paternal figure. This was the paternalism of discipline and of saving others from their bad instincts (see Thomas, 2016). This paternal role is predicated on giving advice - a natural extension of gaming journalists' history of serving as a sort of purchasing guide - but not an extension welcomed by a portion of their audience. They articulated this role through indicating how they envision their audience. This role was used for paradigm repair by discursively framing arguments about the motivations for the harassment of women and, in some cases, by disregarding the ethical allegations aimed at the journalists, such as lack of transparency about close ties to the gaming industry. Simply put, they dismissed the legitimacy of the GamerGate ethical allegations because of the widespread harassment that accompanied the charges.

In discursively constructing their role, gaming journalists largely identified themselves as part of the gaming family and thus as closely related to their audience. The 
gaming journalist's audience are people who play video games, and yet that group is so large - 63 percent of American households - that it is largely unwieldy (Industry Facts, 2016). As this controversy illustrates, this audience includes gamers from a 'masculine gaming culture' actively interested in excluding women from participation (Chess and Shaw, 2015: 208). Gaming journalists responded to the ethical questions regarding their work with willingness and eagerness, yet they quickly pushed attention to the gamers' harassment of women in order to condemn it. For example, in Kotaku's post 'About GamerGate', Editor-in-Chief Stephen Totilo (2014b) notes,

I'm a gamer. I don't mind the term. If you do, that doesn't bother me. I'm confident in who I am. If you're a gamer who harasses, who sends rape threats or stalks Twitter feeds or terrorizes people from their home or gloats at others' struggles - Find a new hobby. If you're a gamer who wants better games reporting? Be specific about what you dislike. Please seek, support and celebrate those whose work you do like.

Throughout the discourse, journalists were eager to respond to the harassment, perhaps because they are also 'gamers'. However, journalists put discursive distance between themselves and their audience by asserting and practicing a paternal role - a role where they acted as disciplinarian and moral voice.

This role bore some similarity to a more traditional watchdog or adversarial role. However, the subject of the role was not the government or a corporation but the gaming press' own audience. One participant in the study (Participant C) noted that the event in its entirety showcased a disconnection with a portion of his audience. This supports the idea that gaming journalists felt compelled to guide their audience, not just to be adversarial to it. So, while the gamers who only wanted the traditional buyers' guide claimed journalists were rejecting them as an audience (Cote, 2015; Goodchild, 2014b), journalists saw an expanded, paternal relationship and role.

Journalists engaged in paradigm repair in some cases by attempting to discursively frame the harassment perpetrated by their audience. In a sense, journalists modeled their professional obligation by attempting to distill the motivations of those involved in the harassment. This falls in line with Totilo's (2014c) argument that gaming journalism should be about the people playing games - not just previewing new releases. The discursive strategy employed here is one of explanation. While the journalists were discussing the motives of those behind the harassment, they were simultaneously contrasting those motives to their own. The motivation behind the harassment was fear, according to one interviewee (Participant I). The informant noted that he shared an important commonality with those conducting harassment in that they all love video games. But he added, 'I think people ... feel that through the criticism, video games are hurt, and that critics weaken them' (Participant I). As a result, those conducting the harassment feel that the kinds of games they love will be taken from them if they are subjected to certain kinds of intense criticism (Stuart, 2014). He voiced disagreement with that notion - 'the outcome of having stronger criticism is more voices in criticism and better video games' (Participant I).

Some journalists were unwilling to acknowledge the ethics aspect of GamerGate, arguing that giving credence to ethics complaints ultimately legitimized the harassment 
(Participant I, Participant J). This is also a way in which paradigm maintenance occurred. Journalists expressed that the harassment threatened to delegitimize their craft, not because of problems with their journalism, but out of disgust with the audience (Totilo, 2014d).

The gaming journalists sometimes discursively expressed their role in explicitly paternal or maternal ways - swinging between parental pride and impatience. Plante (2014) argued that GamerGate supporters were like the 'obstinate child' who throws a temper tantrum, except 'the people behind these temper tantrums are hurting others ... It's time to grow up'. Similarly, McNamara (2014) wrote, 'We have not covered the movement at Game Informer up to this point because we feel that the moniker misrepresents the issues'. This approach amounts to a sort of punishment of those involved in the harassment by not granting them coverage. In this case, the discursive strategy employed was one of creating distance from gaming bullies by declining to respond to the ethics allegations.

Participant $\mathrm{C}$ similarly noted that some gaming journalists were unwilling to discuss the ethical issues in GamerGate, yet very few journalists actually wanted to dismiss the claims outright. Most journalists did say they struggled with how to address the ethical allegations while also making sure to express disgust with the harassment of female game developers and critics. The journalists interviewed in this study, and indeed, the majority of articles did address the ethical allegations raised regarding their role and their connection with the gaming industry.

In articulating their role in terms of paternalism, gaming journalists extended their role of providing purchasing advice to providing moral advice and judgment. In seeking to repair their paradigm, journalists sought to distance themselves from vocal gamers who were engaging in online harassment of women. In some cases, journalists went so far as to avoid engaging in the ethics discussion of GamerGate altogether in order to avoid providing legitimacy to such gamers.

\section{Role of traditional journalism}

As one gaming journalist puts it, 'There's good journalism and shitty journalism everywhere' (Participant A). It was a statement that applied to gaming journalists, but also to all kinds of journalists. Some of the discourse acknowledged that bad gaming journalists were no doubt guilty of some of the things for which they were criticized, such as taking gifts from the gaming industry. But these 'bad apples' were portrayed as holdovers from a past era, before a professional turn in gaming journalism in the last decade. The gaming journalists studied here defended good gaming journalism as no different from 'traditional journalism', to use the label of one participant (Participant G). Gaming journalists served the same kinds of roles and delivered the same kinds of social benefits as traditional journalism. This discourse served as its own kind of paradigm repair. It marked the controversial gaming journalism as unworthy of the label of journalism and posited common cause with the role performed by good journalists everywhere.

The gaming journalists made common cause with traditional journalism in a variety of ways. One of the chief discursive strategies noted that the role played by good gaming journalism was the role played by all good journalism. The role of a journalist is to tell 
the truth, and gaming journalists proudly claimed this was the role they performed, often in the face of game industry resistance and audience indifference. As one puts it, 'you are seeking the truth and your intention is to deliver that truth to an audience that needs it' (Participant G). Gaming journalists were also disseminators of information, just like all journalists. As one puts it, they are all 'focused on getting the news up as quickly as possible' (Participant D).

But, above all, gaming journalists discursively constructed their role as being facilitators for the exchange of socially relevant discussion and debate: gaming journalists were 'improving the conversation culturally about what it means to play video games' (Participant A) and 'engage with gamers' about social issues (Kain, 2014b). Thus, gaming journalists were critics - not just reviewers, but adversaries of practices harmful to the public good (Totilo, 2014d), and facilitators of a 'safe space for our readers, writers and contributors' (Grant, 2014). Indeed, nearly all of the game journalists said journalists were targeted in GamerGate because they advocated for diversity and inclusiveness in the gaming industry. They nearly all pledged to redouble those efforts in the face of criticism and harassment. Thus, the gaming journalists emphatically defended their journalism in normative terms - they were critics of sexist and violent depictions in games and promoters of a diverse public sphere and civil dialogue. The gaming journalists discursively attached their work to the role of all journalism. Thus, the paradigm was sound, as sound as the journalism field in general.

Another discursive strategy noted that good gaming journalists followed the same standards and guidelines practiced by all journalists. For example, they followed the Society of Professional Journalists' 'code of ethics' (Grant, 2014); they avoided conflicts of interest and the game industry had no effect on 'our editorial decision-making process' (McNamara, 2014); they were 'straightforward' with readers (Participant P), 'upfront' about professional relationships (McNamara, 2014), and practitioners of 'transparency' (Grant, 2014). They told readers that 'inquiry is always welcome' (Totilo, 2014a), they looked through the 'bullshit of the surface' to find the stories (Kuchera, 2014), they followed processes for sound 'research' (Participant G) and for 'meticulous editing' (Participant I), and they did 'investigative reporting' (Totilo, 2014d).

Ultimately, they claimed, gaming journalists had become highly professional in their journalistic practice in recent years. Gaming journalists belonged to professional development associations, as journalists of all sorts have since the 19th century (Grant, 2014), and they had journalism degrees (Participant E). As one gaming journalist boasted, 'Journalism about video games is better than it's ever been' (Participant J). Or, as another said, the 'writing has improved dramatically and the coverage has improved dramatically' (Participant G). Even if the professionalization of gaming journalism was not complete, it had 'gotten much better' (Participant C). What's more, 'the act of journalism' that gaming journalists accomplished was far from easy - they got the 'true story the best you can' in the face of a 'locked down', and uncooperative gaming industry (Participant I). Gaming journalists might have faced an even tougher challenge than other journalists, since video games were 'hard enough to describe in the first place, but now you have to figure out how to describe in a traditional journalism sense' (Participant $\mathrm{H}$ ).

The gaming journalists' argued that criticism of their craft was in line with criticism of all journalism. Sometimes that criticism was warranted; although criticism about 
being too dependent on industry sources was 'an issue in journalism everywhere' (Grant, 2014). As one journalist puts it, "these problems are faced in other areas of journalism as well', including 'politics' (Kain, 2014a). Simply put, criticism of 'the press' was as old as the press itself (Gera, 2014). And gamer critics, the argument went, used the same trite criticisms used against all journalists - for instance, they are too 'liberal' (Gera, 2014) or 'biased' (Kain, 2014a). What's more the critics were largely of the same cloth as those finding fault with other sound journalism - they were 'Tea-Party-ish' groups (Participant J) and 'reactionary moral campaigners' (Stuart, 2014) who spun 'conspiracy theories' (Totilo, 2014b). Old forms of press criticism had been dismissed, and so, the argument went, should the criticism of gaming journalism. Implicit in this discursive strategy was also a call to all professional journalists, who had no doubt been unfairly criticized in the past, to come to the defense of gaming journalists.

Finally, gaming journalists pointed out that the topic they covered differed little from other topics covered by other journalists. The video game industry was big business, reaching a 'demographic ... worth billions of dollars to companies and shareholders' (Watson, 2014). The journalists saw an obligation to address it. Chris Suellentrop wrote in The New York Times, 'I used to cover things like presidential campaigns ... at some point, video games began to seem as consequential as those subjects, if not more so' (Suellentrop, 2014). Thus, gaming journalists were covering tough and important social issues, such as demeaning depictions of women in video games. If anything, this work surpassed 'human interest' journalism (Participant $\mathrm{H}$ ) and, as one editor puts it, his writers 'are pursuing what I consider to be real news' (Participant D). Again, gaming journalists sought protection within the familiar and, to their way of thinking, still legitimate paradigm of traditional journalism.

\section{Conclusion}

The paradigm repair performed by gaming journalists bears similarities to other instances of paradigm repair discussed in the existing literature. Gaming journalists divided the field into good and bad journalism, attached themselves to the good, and marginalized the bad (Hindman, 2005). As was the case with Princess Diana's death, the criticism came from the public (Hindman, 2003). And yet, the GamerGate criticism was more of a mixed bag: some elements of public criticism were more typical - calls for journalists to maintain professional independence from industry officials, academics, and other journalists and for transparency in relationships that did exist; but other elements of public criticism were less typical - calls for journalists to jettison their paternal role in critiquing gamer culture and a social justice orientation in order to focus as a buyers' guide. Journalists responded by articulating their role in two ways: as a paternal figure and as a traditional journalist. Journalists adopted a paternal figure role by providing a moral, disciplinary voice to their audience - gamers - a niche group of which gaming journalists are largely members. In adopting this role, journalists repaired their paradigm discursively in two ways: by trying to explain the actions of a minority in their community to a larger audience and by dismissing the ethical charges altogether - an action justified by the fact that many of the claims were baseless (Totilo, 2014a). In trying to explain the action of harassment to their larger audience, gaming journalists were trying 
to understand the connection between the ethical charges regarding their work and the harassment of women in gaming and gaming criticism. There was no rational explanation for the harassment done to women; yet gaming journalists attempted to understand and convey that understanding since gamers, the community the journalists cover, perpetrated the harassment. Yet in other cases, this paternalistic role encouraged journalists to largely dismiss the charges outright, in that they viewed the harassment as delegitimizing the ethical charges made against them. This is a moral, disciplinary judgment, which argues that those conducting the harassment do not deserve to be granted a voice.

Journalists also adopted the role of the traditional journalist, linking themselves with established journalistic entities and practices. Journalists engaged in paradigm repair through this role, both in interviews and in published articles, by discursively linking their work to professional journalistic organizations, such as the Society for Professional Journalists, and by noting their similarities with traditional journalism - gaming journalists performed similar roles, followed similar guidelines of professionalism, faced the same set of marginalized critics, and provided real news about a culturally and economically important industry. The journalists acknowledged that gaming journalism had suffered from inadequacies in the past; these had been the unwritten assumptions of the old paradigm (Bennett et al., 1985; Carlson, 2012) that they were now ready to explicitly address. Thus, in face of the GamerGate criticism, the journalists decisively broke with the old paradigm of an enthusiast-press and claimed their place within the paradigm of traditional, public-minded journalism.

This research adds to the literature in a number of ways. It provides shape to how lifestyle journalists might conduct paradigm maintenance. Prior research into paradigm maintenance largely examined the repair process as traditional journalists performed it. As Hanusch (2014) noted, there has been a shift in the journalistic field toward a greater focus on lifestyle journalism. Gaming journalism is an example of lifestyle journalism in that implicit in the specialty is the idea that gaming journalism provides purchasing guidance. Yet, as this study demonstrates, in the process of paradigm repair, this guidance function was emphasized more heavily. Gaming journalists went beyond advice on what to purchase to providing moral judgments on behavior. Simultaneously, gaming journalists performing paradigm repair linked themselves to more hard news and traditional journalistic sources to support the way they work.

Even though there appears to be a shift underway toward lifestyle journalism, these particular lifestyle journalists - when confronted with an ethical controversy - wanted to link their work with the roles, ethical procedures, and professional practices of traditional journalists. This is consistent with Reese's (1990) and Berkowitz's (2000) argument that members of a field seek legitimacy by positioning themselves within the agreed upon boundaries of the paradigm. The gaming journalists rejected the notion that they were simply reviewers. They argued they played an important social role - critic and adversary of sexism and violence in games - which was vital to a healthy, inclusive, and diverse public sphere. While the gaming journalists did not explicitly tie their journalism to serving the cause of democratic self-governance, which remains at the root of most Western normative theorizing about journalism (Christians et al., 2009), they nevertheless implied as much. Gaming may not be a matter of public policy, but the gaming journalists discursively constructed their work as valuable to the marketplace of ideas 
and to civic and personal well-being. This falls in line with the paternal role posited by Thomas (2016) - the journalists justified their work in terms of improving public life. In making these claims, the gaming journalists reaffirmed the norms of traditional journalism.

The fact that gaming journalists themselves performed the paradigm repair is important - it meant they could legitimize their own field. Journalists had done paradigm repair following Princess Diana's death by essentially expelling the paparazzi from the fraternity of journalism (Berkowitz, 2000; Hindman, 2003). Here, with gaming journalists engaged in their own paradigm repair, they discursively attached themselves to the paradigm of traditional journalism and hence to the legitimacy it afforded.

Furthermore, the use of interviews in this study helped to make ideas that could be inferred from the texts more explicit. While the gaming journalism texts used the roles of traditional journalist and paternal figure in responding to the ethics allegations, the interviews indicated how these roles worked to repair the paradigm. Hence, this study showcases that the use of interviews for paradigm maintenance research can be useful in unpacking the operation of paradigm repair.

This research is rooted in the interpretivist and culturalist traditions and, as such, no claims can be made as to the generalizability of the study. And while these traditions assume that the interpretations are unavoidably those of the researchers and not objective descriptions of the texts (Hesse-Biber, 2010), it should be noted that the co-authors arrived at agreement on the interpretations offered here. It must be acknowledged that the development of GamerGate in the midst of the study, while fortuitous in terms of understanding the operation of paradigm repair while it was occurring, also limited the interview sample. Several gaming journalism organizations refused interviews during the controversy, and, as a result of the rampant harassment of women during the study, only two women consented to be interviewed. It is possible that the lack of involvement from female gaming journalists and the lack of input from journalists from a few key journalistic entities could have skewed responses. For example, both female participants noted that they felt a responsibility to promote independent games - games from small developers. This was not represented in the rest of the data. With a greater number of female participants, it is possible that the promotion of smaller, experimental, and at times paradigm-challenging games could have been seen as an additional role for journalists to develop or maintain.

Journalism studies scholarship would benefit from additional research regarding gaming journalism. As a relatively new form of lifestyle journalism, it has routinely needed to confront issues in the gaming community before they hit the American mainstream, such as bullying via social networks, male identity crisis, and ethical concerns regarding augmented and virtual reality. Thus, this particular niche presents a fruitful area of study in that it portends topics of broader cultural concern. In addition, journalism studies scholarship would benefit from additional research into how lifestyle journalists conduct paradigm repair. As Hanusch (2014) noted, in the shifting journalistic paradigm, lifestyle journalism is receiving greater emphasis. Yet, extant studies of paradigm repair largely focus on traditional journalism. Hence, it would worth conducting further examination into how other niches within lifestyle journalism conduct paradigm maintenance. 


\section{Funding}

The author(s) received no financial support for the research, authorship and/or publication of this article.

\section{Note}

1. Joystiq was the first among these to appear on the Internet in June 2004. During the time of this study, in February 2015, Joystiq closed due to declining readership (Crescente, 2015). The interviews from Joystiq were conducted prior to the closure of the website.

\section{References}

Alba-Juez L (2009) Perspectives on Discourse Analysis: Theory and Practice. Newcastle upon tyne, United Kingdom: Cambridge Scholars Publishing.

Bennett W, Gressett LA and Haltom W (1985) Repairing the news: A case study of the news paradigm. Journal of Communication 35: 50-68.

Berkowitz D (2000) Doing double duty paradigm repair and the Princess Diana what-a-story. Journalism 1: 125-143.

Burr V (1995) An Introduction to Social Constructionism. London: Routledge.

Carlson M (2012) 'Where once stood titans': Second-order paradigm repair and the vanishing US newspaper. Journalism 13: 267-283.

Carlson R (2009) 'Too Human' versus the enthusiast press: Video game journalists as mediators of commodity value. Transformative Works and Cultures 2 .

Casti T (2014) Women play video games. Can we cut the sexist crap now? Huffington Post, 27 April. Available at: http://www.huffingtonpost.in/entry/female-gamers_n_5207137

Chess S and Shaw A (2015) A conspiracy of fishes, or, how we learned to stop worrying about gamergate and embrace hegemonic masculinity. Journal of Broadcasting \& Electronic Media 59(1): 208-220.

Christians C, Glasser T, Mcquail D, et al. (2009) Normative Theories of the Media. Urbana, IL; Chicago, IL: University of Illinois Press.

Coddington M (2012) Defending a paradigm by patrolling a boundary: Two global newspapers' approach to WikiLeaks. Journalism \& Mass Communication Quarterly 89: 377 396.

Cote AC (2015) Writing 'gamers': The gendered construction of gamer identity in Nintendo power (1994-1999). Games and Culture. Epub ahead of print 31 December. DOI: 10.1177/ 1555412015624742 .

Crescente B (2015) Joystiq is closing and I'll miss them like hell. Polygon. Available at: http:// www.polygon.com/2015/1/30/7945625/joystiq-is-closing-and-ill-miss-them-like-hell

Foxman MH and Nieborg DB (2016) Between a rock and a hard place: Games coverage and its network of ambivalences. Journal of Games Criticism 3(1): 1-51.

Fürsich E (2012) Lifestyle journalism as popular journalism: Strategies for evaluating its public role. Journalism Practice 6: 12-25.

Gans HJ (1979) Deciding What's News: A Study of CBS Evening News, NBC Nightly News, Newsweek, and Time. Evanston, IL: Northwestern University Press.

Gera E (2014) The war against critics is as old as the printing press, GamerGate is just another example. Polygon. Available at: http://www.polygon.com/2014/12/10/7294207/gamergatemedia-will-self-marx

Golding D (2014) The end of gamers. Dan Golding. Available at: http://dangolding.tumblr.com/ post/95985875943/the-end-of-gamers 
Goodchild J (2014a) Answers. Pixietalksgamergate. Available at: https://pixietalksgamergate. wordpress.com/category/answers-2/

Goodchild J (2014b) 'Gamers are dead' article analysis. Pixietalksgamergate. Available at: https:// pixietalksgamergate.wordpress.com/gamers-are-dead-article-analysis/

Grant C (2014) On GamerGate: A letter from the editor. Polygon, 17 October. Available at: http:// www.polygon.com/2014/10/17/6996601/on-gamergate-a-letter-from-the-editor

Hall S (1980) Encoding/decoding. Culture, Media, Language 128-138.

Hanitzsch T. (2007) Deconstructing journalism culture: Toward a universal theory. Communication Theory 17: 367-385.

Hanusch F (2014) Lifestyle Journalism. New York: Routledge.

Hesse-Biber SN (2010) Mixed Methods Research: Merging Theory with Practice. New York: Guilford Press.

Hindman EB (2003) The princess and the paparazzi: Blame, responsibility, and the media's role in the death of Diana. Journalism \& Mass Communication Quarterly 80: 666-688.

Hindman EB (2005) Jayson Blair, the New York Times, and paradigm repair. Journal of Communication 55: 225-241.

Hindman EB and Thomas RJ (2013) Journalism's 'crazy old aunt' Helen Thomas and paradigm repair. Journalism \& Mass Communication Quarterly 90: 267-286.

Industry Facts (2016) Entertainment software association. Available at: http://www.theesa.com/ about-esa/industry-facts/ (accessed 15 September 2016).

Johnstone JW, Slawski EJ and Bowman WW (1972) The professional values of American newsmen. Public Opinion Quarterly 36: 522-540.

Kain E (2014a) GamerGate: A closer look at the controversy sweeping video games. Forbes, 4 September. Available at: http://www.forbes.com/sites/erikkain/2014/09/04/gamergate-acloser-look-at-the-controversy-sweeping-video-games/

Kain E (2014b) It's time for video game journalists to engage with \#GamerGate. Forbes, 6 October. Available at: http://www.forbes.com/sites/erikkain/2014/10/06/its-time-for-videogame-journalists-to-engage-with-gamergate/\#277b4bf62442

Kaplan S (2014) With \#GamerGate, the video-game industry's growing pains go viral. The Washington Post, 12 September. Available at: http://www.washingtonpost.com/news/morning-mix/wp/2014/09/12/with-gamergate-the-video-game-industrys-growing-pains-go-viral/

Kuchera B (2014) GamerGate, criticism, ideology and 'They Live'. Polygon. Available at: http:// www.polygon.com/2014/11/17/7235801/game-criticism-ideology-gamergate-and-they-live

Kuhn TS (2012 [1970]) The Structure of Scientific Revolutions. Chicago, IL: University of Chicago Press.

Lapinski MK and Rimal RN (2005) An explication of social norms. Communication Theory 15: $127-147$.

Lasswell HD (1948) The structure and function of communication in society. The Communication of Ideas 37: 215-228.

McNamara A (2014) Game informer's stance on GamerGate. Game Informer. Available at: http:// www.gameinformer.com/b/news/archive/2014/10/20/game-informer-on-gamergate.aspx

Massanari A (2015) \#GamerGate and the Fappening: How Reddit's algorithm, governance, and culture support toxic technocultures. New Media \& Society. Epub ahead of print 9 October. DOI: $10.1177 / 1461444815608807$.

Nieborg DB and Sihvonen T (2009) The new gatekeepers: The occupational ideology of game journalism. In: Breaking New Ground: Innovation in Games, Play, Practice and Theory. Proceedings of the Digital Games Research Association, Brunel, United Kingdom.

Plante C (2014) An awful week to care about video games. Polygon, 28 August. Available at: http://www.polygon.com/2014/8/28/6078391/video-games-awful-week 
Reese SD (1990) The news paradigm and the ideology of objectivity: A socialist at the Wall Street Journal. Critical Studies in Media Communication 7: 390-409.

Steiner L, Mccaffrey R, Guo J, et al. (2013) The wire and repair of the journalistic paradigm. Journalism 14: 703-720.

Stuart K (2014) Zoe Quinn: All GamerGate has done is destroy lives. The Guardian, 3 December. Available at: http://www.theguardian.com/technology/2014/dec/03/zoe-quinn-gamergateinterview

Suellentrip C (2014) Can video games survive? The disheartening GamerGate campaign. The New York Times, 25 October. Available at: http://www.nytimes.com/2014/10/26/opinion/sunday/ the-disheartening-gamergate-campaign.html?_r $=0$

Thomas R (2016) In defense of journalistic paternalism. Journal of Mass Media Ethics 31(2): 86-99.

Totilo S (2014a) From the editor in Chief. Kotaku. Available at: http://kotaku.com/in-recent-daysive-been-asked-several-times-about-a-pos-1624707346

Totilo S (2014b) About GamerGate. Kotaku. Available at: http://kotaku.com/about-gamergate-1630707501

Totilo S (2014c) The future of Kotaku's video game coverage is the present. Kotaku. Availble at: http://kotaku.com/the-future-of-kotakus-video-game-coverage-is-the-prese-1644297778

Totilo S (2014d) We're all tired of GamerGate. Kotaku. Available at: http://kotaku.com/were-alltired-of-gamergate-1648624281

Van Dijk, TA (1977) Text and Context Explorations in the Semantics and Pragmatics of Discourse. New York: Longman.

Van Dijk T (1988) News as Discourse. Hillsdale, NJ: Lawrence Erlbaum Associates.

Watson T (2014) What fuels 'GamerGate' anger and outrage? Gender, power and money. Forbes, 20 October. Available at: http://www.forbes.com/sites/tomwatson/2014/10/20/what-fuelsgamergate-anger-and-outrage-gender-power-and-money/\#7161345338a4

Weaver DH and Wilhoit GC (1991) The American Journalist: A Portrait of US News People and Their Work. Bloomington, IN: Indiana University Press.

Weaver DH and Wilhoit GC (1996) The American Journalist in the 1990s: US News People at the End of an Era. London: Psychology Press.

Weaver DH, Beam RA, Brownlee BJ, et al. (2007) The American Journalist in the 21st Century: US News People at the Dawn of a New Millennium. London: Routledge.

Weiss RS (1994) Learning from Strangers: The Art and Method of Qualitative Interview Studies. New York: Simon \& Schuster.

Wright CR (1960) Functional analysis and mass communication. Public Opinion Quarterly 24: 605-620.

Zelizer B (2004) Taking Journalism Seriously: News and the Academy. London: SAGE.

\section{Author biographies}

Gregory P Perreault is an assistant professor of Multimedia Journalism at Appalachian State University. His research areas include media sociology, media paradigms, and media and religion. His work has appeared in the Howard Journal of Communications and the Journal of Media and Religion.

Tim P Vos is chair and associate professor of Journalism Studies and Coordinator of Global Research Initiatives at the University of Missouri School of Journalism. His research areas include media sociology, policy, and history. He is co-author of Gatekeeping Theory and co-editor of Gatekeeping in Transition. 